\title{
Independência ou Norte: reflexões sobre a influência do estrangeirismo no campo do conhecimento da administração no Brasil
}

\author{
LUCAS ROCHA JUNCKLAUS

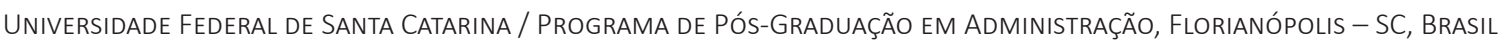 \\ TIAGO JOSÉ BINI

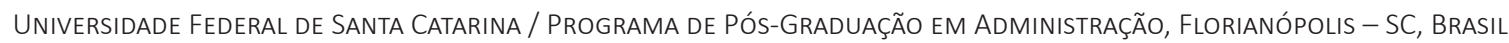

LUIS MORETTO NetO

CENTRO UNIVERSitÁRIO UNIVERSITÁRIO INTERNACIONAL-UNINTER, CURITIBA- PR, BRASIL

\begin{abstract}
Resumo
Este ensaio teórico levanta os principais aspectos da formação da teoria da administração e realiza uma aproximação com a abordagem de Boaventura de Sousa Santos, que advoga uma epistemologia do Sul. Evidencia-se que a ciência positivista demarcou o que é válido como conhecimento e excluiu o que fica além desse "cânone científico". Em síntese, toda e qualquer produção científica fora dos padrões considerados verdadeiros e aceitos pela academia mundial torna-se inválida. Sob essa perspectiva, a obra de Boaventura de Sousa Santos, particularmente a sociologia das ausências e emergências, destaca a hegemonia dos valores notados no processo de interpretação e condução das pessoas em sociedade sob a óptica hegemônica do Norte. Assim, foi traçada uma linha (invisível) abissal, que demarca como válidas somente as experiências do Norte, produzindo ausências epistemológicas nos demais países que, por condições determinantes de sua história como colônias, importaram teorias. Por meio de um ensaio teórico, apresentamos a influência do estrangeirismo na ciência administrativa e as contribuições de Boaventura de Sousa Santos, as quais podem inspirar a construir um conhecimento emancipatório e interdisciplinar, de modo que a administração também utilize sua ecologia de saberes para superar suas ausências epistemológicas.
\end{abstract}

Palavras-chave: Ecologia de saberes. Epistemologias do Sul. Estrangeirismo.

\section{Independence or North: reflections on the influence offoreignness in the administration knowledge field in Brazil}

\begin{abstract}
This theoretical essay surveys the main aspects in the formation of administration theory and it provides a closer look at the approach by Boaventura de Sousa Santos, who advocates for an epistemology of the South. It is observed that the positivist science has demarcated what is valid as knowledge and it has excluded what is beyond this "scientific canon". In short, any scientific work outside the patterns regarded as true and accepted by the global academy becomes invalid. From this perspective, the work by Boaventura de Sousa Santos, particularly the sociology of absence and emergence, highlights the hegemony of values noticed in the process of interpreting and leading people in society from the North's hegemonic viewpoint. Thus, an abyssal (invisible) line was drawn, which demarcates as valid only the North's experiences, producing epistemological absence in the other countries that have, due to determining conditions of their history as colonies, imported theories. By means of a theoretical essay, we introduce the influence of foreignness on the administrative science and the contributions by Boaventura de Sousa Santos, which can inspire the construction of an emancipatory and interdisciplinary knowledge, so that administration also use its knowledge ecology to overcome its epistemological absence.
\end{abstract}

Keywords: Knowledge ecology. Epistemologies of the South. Foreignness.

\section{Independencia o Norte: reflexiones acerca de la influencia del extranjerismo en el campo del conocimiento de la} administración en Brasil

\section{Resumen}

Este ensayo teórico plantea los principales aspectos de la formación de la teoría de administración y hace una aproximación con el enfoque de Boaventura de Sousa Santos, que aboga por una epistemología del Sur. Es evidente que la ciencia positivista demarcó lo que es válido como conocimiento y excluyó lo que está fuera de este "canon científico". En pocas palabras, las producciones científicas fuera de las normas consideradas verdaderas y aceptadas por la academia mundial dejan de ser válidas. Desde esta perspectiva, el trabajo de Boaventura de Sousa Santos, en particular la sociología de las ausencias y emergencias, destaca la hegemonía de los valores observados en el proceso de interpretación y conducción de las personas en la sociedad bajo la perspectiva hegemónica del Norte. Así, se trazó una línea (invisible) abismal, que demarca como válidos sólo las experiencias del Norte, produciendo ausencias epistemológicas en los otros países que, mediante factores determinantes de su historia como colonias, importaron teorías. A través de un ensayo teórico, presentamos la influencia del extranjerismo en la ciencia administrativa y las contribuciones Boaventura de Sousa Santos, que pueden inspirar la construcción de un conocimiento emancipatorio e interdisciplinario, de modo que la administración también utilice su ecología de saberes para superar sus ausencias epistemológicas.

Palabras clave: Ecología de saberes. Epistemologías del Sur. Extranjerismo.

Artigo submetido em 10 de agosto de 2014 e aceito para publicação em 29 de janeiro de 2015.

DOI: http://dx.doi.org/10.1590/1679-395131513 


\section{INTRODUÇÃO}

Para perceber e entender a fragilidade e a delicadeza dos estudos organizacionais no Brasil, buscou-se o sociólogo português Boaventura de Sousa Santos (2010), que sugere uma "epistemologia do Sul", partindo do pressuposto de que existe uma epistemologia - dominante e hegemônica - do Norte. Sua obra e seu olhar crítico são indispensáveis para essa verificação.

O projeto de Santos (2007) busca encontrar as bases e as possibilidades da reinvenção da emancipação social nas realidades dos países periféricos. O argumento central é de que existe uma reiterada tensão e crise entre a regulação e a emancipação social e entre a experiência e as expectativas na sociedade moderna ocidental. No plano social, há uma regressão agravada, sobretudo nas últimas décadas, com perdas de direitos e de possibilidades futuras e, no plano epistemológico, a crise do pensamento hegemônico das ciências sociais, centradas em uma razão eurocêntrica e indolente, incapazes de produzir novas ideias.

Santos (2006a) faz emergir uma crítica à racionalidade ocidental dominante nos últimos duzentos anos para propor um modelo diferente de racionalidade, que torne visíveis as iniciativas e os movimentos alternativos e valorize a experiência e a riqueza social das nações que foram ocultadas pela teoria social (SANTOS, 2006a).

Do ponto de vista ético, assim como Fanon (1979) trabalha a óptica dos condenados da terra, as epistemologias do Sul propõem uma construção dialógica e processual de outro paradigma de vida, com justiça, solidariedade e respeito à diversidade. Streck e Adams (2012) corroboram esse pensamento de similaridade entre Santos (2006a) e Fanon (1979). Nesse sentido, Dussel (2010) aponta a condição histórica de dominação e subalternidade do Sul; no entanto, não propõe uma inversão, mas um diálogo ético de condições igualitárias com a ciência positivista. Santos (2010) afirma, ainda, a necessidade da dialogicidade entre conhecimentos para superar o pensamento abissal e a mudança de papel de colonizado para participante ativo.

No campo da administração no Brasil os aspectos do "Sul" fragilizado são percebidos por meio da importação de teorias. Em estudo recente, Bertero, Alcadipani, Cabral et al. (2013) apresentam que o mais frequente problema seria o estrangeirismo, que é clara manifestação de sentimento de inferioridade. O estrangeirismo é observado com frequência na produção científica da área e no comportamento do pesquisador brasileiro em administração. Essa tendência de supervalorizar o estrangeiro advém de um histórico originado no passado colonial do Brasil. Segundo os autores, "o desequilíbrio do estrangeirismo seria a sobrevalorização do que é estrangeiro pelo simples fato de ser estrangeiro e isso traz implícita a colocação de que somos inferiores" (BERTERO, ALCADIPANI, CABRAL et al., 2013, p. 182).

Para Santos (2010), os países que tiveram um passado colonial, portador de uma ideologia subjacente a um sistema de dominação, ainda hoje possuem relações sociais desiguais em seu interior ocasionadas pelo colonialismo em sua forma de poder e saber.. Assim, para o sociólogo, o colonialismo, além de todos os efeitos de dominação conhecidos, também ocasionou uma dominação epistemológica que se efetivou em uma relação desigual entre saberes, conduzindo à eliminação de muitas formas de saber próprias dos povos e das nações colonizadas. O olhar a partir das "epistemologias do Sul" proporciona a valorização de tudo aquilo que a norma epistemológica dominante extinguiu e propõe promover um diálogo horizontal entre conhecimentos, denominado "ecologia de saberes".

A partir dessas considerações iniciais, este artigo tem por objetivo apresentar as contribuições do pensamento do sociólogo Boaventura de Sousa Santos no campo da epistemologia e dialogar com problemáticas da formação da ciência e do ensino da administração no Brasil, sob os estudos de Serva (1990; 1992), Vergara e Carvalho Jr. (1995), Vergara e Pinto (2001), Rodrigues e Carrieri (2001), Streck e Adams (2012) e Bertero, Alcadipani, Cabral et al. (2013). Para tanto, o artigo aborda o paradigma positivista na ciência e na administração, o pensamento pós-abissal e a ecologia de saberes, a sociologia das ausências e a sociologia das emergências junto com aspectos da tradução elaborados por Santos (2006a) e noção de ecodesenvolvimento de Ignacy Sachs (1986). Dessa forma, o artigo apresenta as inquietações a respeito da importação de teorias na administração e outras dificuldades para construir uma ciência administrativa brasileira.

Este artigo foi elaborado segundo o modelo de um ensaio teórico, portanto, por meio de uma pesquisa bibliográfica, procurou-se realizar uma aproximação entre os temas indicados. Segundo Cervo, Bervian e Silva (2007), essa metodologia 
busca referências teóricas previamente publicadas. Contudo, Marconi e Lakatos (2008) argumentam que a pesquisa bibliográfica não apresenta caráter de reprodução, pois aborda um tema estudado sob perspectiva diferente, evidenciando resultados distintos e inovadores.

Destacam-se como delimitação os autores e trabalhos selecionados. No entanto, também há outros textos relevantes quanto ao estudo da epistemologia da administração. Como ressalta Serva (2013), a busca pela conexão com Boaventura de Sousa Santos decorre da profundidade com que o sociólogo português analisa a crise da ciência na atualidade.

Este ensaio teórico foi dividido em cinco partes além desta introdução: inicia com a evolução do paradigma positivista a partir de Robert King Merton e suas contrariedades com as visões de Boaventura de Sousa Santos; aprofunda a discussão da sociologia das ausências e das emergências; apresenta e discute o estrangeirismo na administração brasileira, apontando a necessidade do trabalho de tradução de Santos; em seguida, busca identificar os desafios do trabalho de tradução no Brasil para a reconstrução do conhecimento na ciência administrativa; e, por fim, apresenta uma conclusão que analisa as perspectivas apresentadas.

\section{A EVOLUÇÃO DO PARADIGMA POSITIVISTA E AS VISÕES DE BOAVENTURA DE SOUSA SANTOS}

De modo amplo, Merton (1970, p. 652) define os quatro sentidos mais habituais do termo ciência: (1) um conjunto de métodos característicos por meio dos quais o conhecimento é avaliado; (2) um acervo do conhecimento acumulado resultante da aplicação dos métodos; (3) um conjunto de valores culturais e normas que presidem as atividades consideradas científicas; (4) uma combinação dos sentidos anteriores. As ciências sociais, principalmente a ciência administrativa, apresentam uma perspectiva positivista que determina quais são as experiências válidas como ciência.

Tenório (1998) argumenta que, para a escola de Frankfurt, o conhecimento positivista é onisciente, pois procura estabelecer princípios gerais, enfatizar o empirismo e identificar proposições gerais, visando ao domínio do conhecimento puro antes da transformação da sociedade. Para Santos (2010), esse pensamento moderno ocidental e positivista é entendido como um pensamento abissal.

O reconhecimento da persistência do pensamento abissal é condição sem a qual não pode ser concebida qualquer forma de pensar ou agir diferente. Segundo Santos (2010), as distinções invisíveis do pensamento ocidental são estabelecidas por meio de linhas que separam a realidade social em dois universos, sendo que o universo moderno faz com que o outro desapareça enquanto realidade. De forma contrária, o pensamento pós-abissal é "um pensamento não derivativo e envolve uma ruptura radical com as formas ocidentais modernas de pensamento e ação" (SANTOS, 2010, p. 53).

Para Santos (2006b, p. 137), atualmente o conhecimento científico é "a forma oficialmente privilegiada de conhecimento e a sua importância para a vida das sociedades contemporâneas não oferece contestação". Dessa forma, todos os países empenham esforços para a promoção da ciência, aguardando benefícios do investimento, que, por sua vez, conferem privilégios extracognitivos (sociais, políticos e culturais) a quem a detém (SANTOS, 2006b). A partir do século XVII, quando a ciência atingiu esse patamar de legitimidade,

[...] o debate sobre o conhecimento centrou-se no interior da ciência moderna, nos fundamentos de validade privilegiada do conhecimento científico, nas relações deste com outras formas de conhecimento (filosófico, artístico, religioso, literário, etc.), nos processos (instituições, organizações e metodologias) de produção da ciência e no impacto da sua aplicação (SANTOS, 2006b, p. 138).

Em consonância com o exposto, a ruptura radical proposta por Santos (2010) pode ser entendida como a quebra de paradigmas de Kuhn (1978). A proposta de Kuhn quanto à possibilidade da quebra de paradigmas surgiu da insustentabilidade da concepção científica tradicional (SANTOS, 1978). A industrialização da ciência, que pretendia significar o clímax da concepção heroica da ciência positivista, foi, no entanto, "realizada de tal modo que o sentido da intervenção da ciência ao nível da produção ideológica acabou por entrar em conflito insanável com o sentido da sua intervenção ao nível da produção material" (SANTOS, 1978, p. 15). A ideia de uma retroalimentação - nesse caso, negativa - firma-se quando Kuhn discorre sobre as universidades, considerando que o estudo de uma ciência normal se transforma em uma disciplina curricular, pois o que está ocorrendo é uma transmissão de paradigmas já impostos: 
[...] o estudo dos paradigmas [...] é o que prepara basicamente o estudante para ser membro da comunidade científica determinada na qual atuará mais tarde. Uma vez que ali o estudante reúne-se a homens que aprenderam as bases de seu campo de estudo a partir dos mesmos modelos concretos, sua prática subsequente raramente provoca desacordo declarado sobre seus pontos fundamentais (KUHN, 1978, p. 30).

Nesse sentido, Kuhn (1978, p. 31) afirma que essa atitude é pré-requisito para a "ciência normal, isto é, para a gênese e a continuação de uma tradição de pesquisa determinada". Bunge (1980, p. 58) discorre sobre o mesmo assunto, a pesquisa básica, afirmando que esta é um instrumento de desenvolvimento técnico, econômico e político. $O$ autor não superestima a ciência normal e afirma que esta e seus pesquisadores não têm competência para abordar os problemas sociais. No entanto, Bunge $(1980$, p. 58) relata que a "ciência básica fornece algumas das ferramentas cognoscitivas necessárias para reconhecer, abordar e resolver" diversos dos problemas sociais.

A partir de Kuhn (1978), é possível desenvolver um esforço sistemático para confrontar essa ideologia analisando as relações de poder dentro e fora da comunidade científica e, dessa forma, esclarecer os mecanismos nos quais se cria o "consenso científico" e se orienta o desenvolvimento da ciência para favorecer sistematicamente certas áreas de investigação e de aplicação, certas metodologias e orientações teóricas, em detrimento de outras. Para Santos (1978, p. 32), "estes processos são depois suscetíveis de uma análise virada para as estruturas do poder científico e do poder tout court na sociedade".

Uma das áreas de investigação diz respeito aos pressupostos metateóricos do trabalho científico. Bernard Barber (1961), um dos discípulos do trabalho mertoniano, descreve uma série de casos em que a resistência, por parte de cientistas a teorias científicas, posteriormente, provou-se correta. Barber (1961) explica essa resistência em função das crenças, incluindo credos religiosos e pré-juízos de escola, dos cientistas. Para Santos (1978), a partir de Kuhn (1978), é possível compreender o pressuposto filosófico-científico dessa investigação, uma vez que a utilização causalista do sistema de crenças somente é considerada nos casos em que estas atuam como fonte de erro e como obstáculo à verdade, todavia, nunca nos casos em que proporcionam a aproximação da verdade. Santos (1978) destaca que, segundo o pensamento de Barber (1961), a verdade científica é derivada do uso correto do método científico, sendo este universal e invariante. Trata-se, pois, da concepção positivista da ciência, onde o método científico valida em absoluto o conhecimento e os "pressupostos metateóricos estão possuídos de negatividade radical" (SANTOS, 1978, p. 33).

Como contraponto dessa hegemonia da ciência moderna, Santos (2006a) apresenta sua pesquisa em cinco países - África do Sul, Brasil, Colômbia, Moçambique e Portugal -, onde evidenciou que a experiência social em todo o mundo é muito mais ampla e variada do que a tradição científica ou filosófica ocidental conhece e considera importante. Além disso, essa riqueza social vem sendo desperdiçada e é desse desperdício que se nutrem as ideias que proclamam que não há alternativa, que a história chegou ao fim. Por fim, para combater o desperdício da experiência, para tornar visíveis as iniciativas e os movimentos alternativos e para lhes dar credibilidade, de pouco serve recorrer à ciência social tal como ela é conhecida, uma vez que essa ciência é responsável por esconder ou desacreditar as alternativas. Para combater o desperdício da experiência social, é necessário propor um modelo diferente de racionalidade. Ainda de acordo com Santos (2006a, p. 94), "sem uma crítica do modelo de racionalidade ocidental dominante [...], todas as propostas apresentadas pela nova análise social, por mais alternativas que se julguem, tenderão a reproduzir o mesmo efeito de ocultação e descrédito".

Segundo Santos (2006b), a premissa da unidade da ciência, crença da cultura ocidental que dominou o início do século $X X$, ainda é vigente em algumas tendências epistemológicas, todavia, cada vez mais confrontada pela premissa da pluralidade, diversidade, fragmentação e heterogeneidade. Essa corrente, que abrange o reconhecimento da pluralidade epistemológica, vai de encontro à visão determinista e reducionista da ciência positivista.

A percepção do autor, de que se deve reconhecer a pluralidade de conhecimentos heterogêneos por meio de interações sustentáveis e dinâmicas, sem que a autonomia de cada conhecimento seja comprometida, origina o termo ecologia de saberes (SANTOS, 2010). 
Santos (2010) argumenta que, na ecologia de saberes, a medida do realismo não é mais a capacidade do conhecimento representar o real, mas, sim, do conhecimento como intervenção no real, ou seja: a credibilidade da construção do conhecimento está em que tipo de intervenção no mundo ela proporciona, ajuda ou impede.

A ecologia de saberes é, segundo Santos (2006b), simultaneamente, uma epistemologia da corrente e da contracorrente, visto que sua condição de possibilidade também é uma dificuldade. Assim, um dos impulsos básicos para sua emergência se dá, principalmente, nos países periféricos.

As resistências ao capitalismo global têm vindo a proliferar na periferia do sistema mundial, num conjunto de sociedades onde a crença na ciência moderna é mais tênue, onde é mais visível a vinculação da ciência moderna aos desígnios da dominação colonial e imperial, e onde outros conhecimentos não científicos e não ocidentais prevalecem nas práticas quotidianas da resistência (SANTOS, 2006b, p. 156).

A partir do pensamento de que a ecologia de saberes acolhe as diversidades epistemológicas e sociais, passa-se a considerar a gestão um campo de surgimento dual, que pode ser pensado e interpretado sem limites ou fronteiras, de que um lado é tão importante quanto o outro (SANTOS, 2010).

De modo contrário, o objetivo de Frederick Taylor (1970, p. 28) de "provar que a melhor administração é uma verdadeira ciência, regida por normas, princípios e leis claramente definidos" demonstra a convergência da chamada administração científica com a perspectiva positivista. Taylor introduziu o estudo de tempos e movimentos dos operários, proporcionando ao empregador métodos para visualizar onde havia desperdício de tempo e, consequentemente, dinheiro. Para Taylor (1970), a administração, até o século XIX conhecida como administração por iniciativa e incentivo, relegava ao trabalhador a decisão de como e em qual ritmo realizar uma tarefa, no entanto, a administração científica apresentava como preeminência a definição das tarefas pela direção, uma vez que esta, e somente esta, era capaz de, por métodos cientificos, encontrar o chamado "the best way"1.

Desse modo, por operar dentro de uma perspectiva positivista, a administração científica se enquadrou nos moldes da "ciência normal", delimitada por Kuhn (1978); segundo o autor, a ciência normal é um instrumento para a resolução de quebra-cabeças que corroboram e sustentam o paradigma atual.

Portanto, a racionalidade hegemônica criticada por Santos (2006a) é denominada "indolente". A razão indolente submete-se, em suas várias formas, ao conhecimento hegemônico, tanto filosófico como cientifico. Dessa forma, nos dois últimos séculos, a razão indolente criou um quadro para os grandes debates filosóficos e epistemológicos, presidindo-os e controlando seus resultados. Por isso, "outros saberes, não científicos nem filosóficos, e, sobretudo, os saberes exteriores ao cânone ocidental, continuaram até hoje em grande medida fora do debate" (SANTOS, 2006a p. 96).

A razão indolente se manifesta de várias formas. Uma delas é a razão metonímica, que tem por concepção que o todo tem absoluta primazia sobre cada uma das partes que o compõem. A razão metonímica não é capaz de aceitar que a compreensão do mundo vai muito além da compreensão ocidental do mundo. Dada a homogeneidade entre o todo e as partes, estas não têm existência fora da relação com a totalidade. No entanto, para o sociólogo, o todo é apenas uma das partes transformada em termos de referência para as demais (SANTOS, 2006a).

A racionalidade ocidental, por meio de uma peculiar concepção de totalidade, caracteriza-se por contrair o presente e, por outro lado, expandir o futuro nas formas lineares do tempo e planificação da história (SANTOS, 2006a). A proposta do autor é uma racionalidade cosmopolita que se concentre em trilhar o caminho contrário: expandir o presente e contrair o futuro.

Para superar a razão indolente, ampliar o mundo e expandir o presente, o autor sugere uma sociologia das ausências e emergências, que tem por objetivo transformar objetos impossíveis em possíveis e, com base neles, transformar ausências em presenças, centrando principalmente nos fragmentos da experiência social não socializada pela totalidade metonímica (SANTOS, 2006a).

${ }^{1}$ Do inglês a melhor forma. Afirmação de Taylor (1970) de que existe uma única forma de executar uma tarefa que é a melhor entre todas as outras. 


\section{A SOCIOLOGIA DAS AUSÊNCIAS E EMERGÊNCIAS}

Há vários modos de produção de não existências, segundo Santos (2006a). Um deles é a monocultura do saber que coloca a ciência moderna e a alta cultura em "critérios únicos de verdade e de qualidade estética" (SANTOS, 2006a, p. 102). Cada uma constitui, assim, em seu campo, "cânones exclusivos de produção de conhecimento ou de criação artística" (SANTOS, 2006a, p. 103). Outra forma é denominada pelo autor monocultura do tempo linear, pois trata o tempo somente de forma unidimensional - os países centrais julgam pelo que são ou pelo que já têm. Isso implica que os países centrais, na vanguarda do tempo, junto com seus conhecimentos e instituições, considerem atrasado "tudo o que segundo a norma temporal, é assimétrico em relação ao que é declarado avançado” (SANTOS, 2006a, p. 103).

A sociologia das ausências visa a superar a monocultura do saber científico por meio de uma ecologia de saberes (SANTOS, 2006a). A experiência social que não entra no cânone moderno é considerada um resíduo. $O$ tempo linear não é capaz de reconhecer experiências contemporâneas de países do Sul. A sociologia das ausências almeja libertar essas experiências do tempo linear e torná-las outras formas de viver socialmente na contemporaneidade, constituindo uma ecologia das temporalidades (SANTOS, 2006a).

Além da dilatação do presente, é preciso uma contração do futuro. A sociologia das emergências é a proposta para isso. Assim, para Santos (2006a, p. 116), ela consiste em "substituir o vazio do futuro segundo o tempo linear (um vazio que tanto é tudo como é nada) por um futuro de possibilidades plurais e concretas, simultaneamente utópicas e realistas, que se vão construindo no presente através das atividades de cuidado".

Para Santos (2006a, p. 118) "a sociologia das emergências é a investigação das alternativas que cabem no horizonte das possibilidades concretas". Assim, a sociologia das emergências também "amplia o presente, juntando ao real amplo as possibilidades e expectativas futuras que ele comporta".

Enquanto a razão proléptica - que não pensa o futuro, pois julga saber tudo a respeito dele e o concebe como uma superação linear, automática e infinita do presente - ampliou as expectativas e, com isso, reduziu o campo das experiências e, portanto, contraiu o presente, "a sociologia das emergências busca uma relação mais equilibrada entre experiência e expectativa, o que, nas atuais circunstâncias, implica dilatar o presente e encurtar o futuro" (SANTOS, 2006a, p. 119). A sociologia das emergências possibilita uma semântica de expectativas que indicam novos caminhos para emancipações sociais (SANTOS, 2006a).

Acerca da conexão das duas sociologias, Santos (2006a, p. 120) discorre: "As duas sociologias estão estreitamente associadas, visto que, quanto mais experiências estiverem hoje disponíveis no mundo, mais experiências são possíveis no futuro". Quanto mais ampla for a realidade credível, mais vasto é o campo dos sinais ou pistas credíveis e dos futuros possíveis e concretos. Na sociologia das ausências, essa multiplicação e diversificação ocorre pela via da ecologia dos saberes, dos tempos, das diferenças, das escalas e das produções, ao passo que a sociologia das emergências as revela por via da amplificação simbólica das pistas ou sinais.

Para Santos (2006a), a lógica da monocultura do saber e do rigor científicos tem de ser questionada pela identificação de outros saberes e de outros critérios de rigor que operam em contextos e práticas sociais declarados não existentes pela razão metonímica. Essa ecologia de saberes possibilita superar a monocultura do saber científico e a ideia de que os saberes não científicos são alternativos ao saber científico, pois, para Santos (2006a), a ideia de alternativo pressupõe a ideia de normalidade, logo, o alternativo recebe uma conotação latente de subalternidade.

A supervalorização do estrangeiro dentro da área da administração e as dificuldades de fazer uma ciência administrativa demonstram esse fato. A razão metonímica nega a universalidade do saber, entende a ciência como um processo acumulativo e não percebe a unidade a partir da diversidade.

A seguir, procura-se mostrar como se deu a consolidação do estrangeirismo na administração e, em resposta, apresentam-se os trabalhos de tradução, que podem ser uma forma de atenuar esse quadro. 


\section{ESTRANGEIRISMO E O TRABALHO DE TRADUÇÃO}

As primeiras escolas de administração no Brasil, segundo Serva (1990), tiveram participação do governo americano e de instituições de Ensino Superior como a Universidade do Estado de Michigan e a Universidade do Sul da Califórnia. As participações se deram por meio de um convênio entre os dois países, que objetivava, principalmente, "ações como assistência técnica para a elaboração de currículos, métodos e técnicas de ensino, instalação de bibliotecas e formação de professores" (SERVA, 1990, p. 10).

Essas escolas superiores de administração foram estimuladas por meio da política desenvolvimentista, adotada a partir dos governos de Getúlio Vargas. O modelo de desenvolvimento almejado foi delineado na experiência das nações ocidentais mais avançadas, resultando daí toda a filosofia que direcionou a criação das escolas de administração no Brasil (SERVA, 1990).

Serva (1990) também destaca que, nesse período, o suporte teórico fornecido pelas escolas brasileiras ao administrador era incompatível com a pluralidade e especificidade de seu campo de atuação. Assim, de acordo com o autor:

[...] as teorias organizacionais e os modelos de gestão são fundamentados pelos paradigmas, ideologias gerenciais, estruturas e necessidades daquele sistema (sistema oligopolizado de produção), gerando um profundo gap entre teoria e prática quando observamos os demais espaços do campo de atuação do administrador (SERVA, 1990, p. 15).

Da mesma forma, Rodrigues e Carrieri (2001, p. 86) ressaltam que "a influência do pensamento anglo-saxônico deu-se não somente por meio das multinacionais que passaram a atuar no Brasil, mas também por meio da influência dos scholars americanos, que contribuíram na fundação dos programas gerenciais".

Assim, a valorização do estrangeiro é muito evidenciada no contexto organizacional brasileiro. Motta, Alcadipani e Bresler (2001) abordam a valorização do estrangeiro como um dos traços culturais marcantes brasileiros. Os autores relatam que, muitas vezes, a valorização do estrangeiro "se dá mascarada por uma pretensa busca de modernidade", e no mundo organizacional o estrangeirismo tem forte papel de segregação de uma classe perante outra (MOTTA, ALCADIPANI e BRESLER, 2001, p. 61).

Desde os anos 1960 nota-se que há um processo intenso de importação de teorias em descrédito a uma produção interna. Serva $(1992$, p. 129) apresenta que tal fato "condiciona a conformidade teórica em face dos 'produtos externos', revelando a sua aceitação imediata, sem os devidos questionamentos", o que leva a imitação desenfreada e uma valorização dos estrangeirismos na área de administração.

Como consequências do estrangeirismo na administração, obtém-se uma teoria funcionalista que somente valoriza a racionalidade de cálculo e utilidade, atributos da racionalidade instrumental. Esses aspectos aparecem nos "manuais" aplicados nos cursos de administração e nas soluções rápidas, práticas e objetivas para problemas de relações de pessoas, esquecendo que são complexas e dotadas de racionalidade substantiva (RAMOS, 1983).

Sachs (1986, p. 82) propõe que o maior perigo é que o importador da ideia "aprende a manipulá-la sem compreender", tornando-se um simples gestor que, quando necessitar de alguma reformulação importante, precisará com urgência da ajuda do idealizador, bloqueando "a vontade da concepção de soluções originais, em nome de uma enganadora economia de esforços".

Assim, trazendo à reflexão um pensamento de Rafael Alcadipani (BERTERO, ALCADIPANI, CABRAL et al., 2013, p. 193), autor que afirma que "temos uma tendência de supervalorizar o estrangeiro; trata-se de um histórico em nosso país originado em nosso passado colonial". Dessa forma, "valorizar o ensino e a pesquisa do Norte como de 'primeira linha' é fundamental para a construção da inferioridade dos brasileiros como pesquisadores" (BERTERO, ALCADIPANI, CABRAL et al., 2013, p. 193), significa, assim, deixar para os autores e pesquisadores boreais o papel de criar modelos, restando aos sulistas ser meros reprodutores. Diante disso, pode-se afirmar que existem empecilhos a uma produção no campo da administração diferenciada no Brasil.

Para analisar quantitativamente os estrangeirismos na administração, Vergara e Pinto (2001) verificaram as nacionalidades dos autores referenciados na literatura brasileira na área de análise organizacional, em estudo comparativo ao trabaIho realizado por Vergara e Carvalho Jr. (1995), e, pela amostra selecionada, recolheram dados referentes a uma década. 
O estudo conclui forte presença estrangeira, com base nas citações de artigos publicados no Encontro da Associação Nacional de Pós-Graduação e Pesquisa em Administração (EnANPAD), Revista de Administração de Empresas (RAE), Revista de Administração Pública (RAP) e Revista de Administração da Universidade de São Paulo (RAUSP). Somando a década (1989 a 1998), as referências americanas são as mais utilizadas (33,09\%), seguidas pelas brasileiras (28,12\%), britânicas (6,51\%) e francesas (5,32\%); Alemanha e Canadá aparecem em menor número, com os percentuais de 2,80\% e $2,41 \%$, respectivamente.

Os autores tecem, assim, algumas considerações sobre esses números e uma possível explicação da prevalência de literatura norte-americana. Para Vergara e Pinto (2001), além das razões de natureza ideológica e de objetivos de consolidação da hegemonia intelectual dos Estados Unidos em relação aos países em desenvolvimento, o uso de suas teorias no Brasil está atrelado a uma produção acadêmica superior em termos quantitativos e a facilidade de acesso, no Brasil, às publicações estadunidenses. Outro motivo apontado é que a construção nacional da área de pesquisa e ensino em administração foi, desde o início, bastante influenciada pelos Estados Unidos, como também é evidenciado por Serva (1990) no início desta seção.

Em um fórum promovido por Bertero, Alcadipani, Cabral et al. (2013, p. 15), que tinha por objetivo fazer um balanço do campo de desenvolvimento científico da administração no Brasil na década de 2000 e indicar caminhos para seu fortalecimento, foi evidenciado que "os pesquisadores brasileiros vêm sistematicamente se apropriando de teorias originadas fora do país, principalmente aquelas dos países anglo-saxões e aplicando-as ao contexto local".

Os autores relatam que, por meio desse processo, são obtidas modernas teorias para explicar fenômenos locais, mas, ao mesmo tempo, evidencia-se que elas devem ser selecionadas de modo a ser válidas quanto à realidade local (BERTERO, ALCADIPANI, CABRAL et al., 2013, p. 15):

[...] mirando o futuro, para que tal processo seja robusto e gere contribuições significativas, é preciso que ocorra uma escolha esclarecida e estratégica das teorias a serem apropriadas e uma aplicação consistente com a realidade local. Para isso, é preciso romper a apropriação superficial de teorias, praticada nos trópicos, e aprofundar efetivamente o conhecimento sobre os corpos teóricos originados em outros contextos (BERTERO, ALCADIPANI, CABRAL et al., 2013, p. 15).

Nesse sentido, o sociólogo Guerreiro Ramos (1996) já advertia em sua obra acerca da maneira de agir dos profissionais que utilizavam teorias importadas onde, segundo ele, considerável parcela de estudiosos seguiram sem se dar conta dos pressupostos históricos e ideológicos do seu trabalho científico. Para Ramos (1996, p. 68), "sua conduta era reflexa e se submetia passiva e mecanicamente a critérios oriundos de países plenamente desenvolvidos". E continua advertindo sobre o contraponto necessário a toda importação de teoria. Por isso, "à assimilação literal e passiva dos produtos científicos importados ter-se-á de opor a assimilação crítica desses produtos" (RAMOS, 1996, p. 68).

Para Guerreiro Ramos (1996, p. 11) era fundamental "pôr em prática a razão sociológica como um instrumento de reflexão a respeito de si com relação à estrutura social à qual estava vinculada". A essa reflexão e sobre a crítica à importação de teorias, o sociólogo chamou de redução sociológica. Assim, Guerreiro Ramos "defende a prática da autoconsciência da sociedade brasileira por meio de uma sociologia engajada com a realidade nacional" (PAES e DELLAGNELO, 2012, p. 7)².

Nesse contexto de diversidade e multiplicidade de experiências disponíveis e possíveis - em oposição a um sistema de importação de teorias -, Santos (2006a) sugere que a formulação de uma teoria geral que capte a totalidade, considerada pelo autor inesgotável, não respeita a heterogeneidade de outras experiências. Por conseguinte, como contraponto, o autor sugere o trabalho da tradução.

A tradução é o procedimento que possibilita criar inteligibilidade recíproca entre as experiências disponíveis e possíveis do mundo. Reveladas pela sociologia das ausências e a sociologia das emergências, trata-se de um procedimento que não atribui a nenhum conjunto de experiências nem o estatuto de totalidade exclusiva, nem o estatuto de parte homogênea

\footnotetext{
${ }^{2}$ Apesar de semelhanças nas teorias relacionadas neste artigo, Alberto Guerreiro Ramos realizou um obra mais ampla e direcionada à realidade nacional brasileira do que Boaventura de Sousa Santos, que trata mais especificamente dos países não hegemônicos.
} 
(SANTOS, 2006a). Não obstante, por meio da tradução, torna-se possível identificar preocupações comuns, aproximações complementares e contradições inultrapassáveis (SANTOS, 2010).

O trabalho de tradução incide tanto sobre os saberes como sobre as práticas e seus agentes. A tradução entre saberes assume a forma de uma hermenêutica diatópica e consiste no trabalho de interpretação entre duas ou mais culturas, com o objetivo de identificar preocupações isomórficas entre elas e suas diferentes respostas. A hermenêutica diatópica parte da ideia de que todas as culturas são incompletas e, portanto, podem ser enriquecidas pelo diálogo e pelo confronto com outras culturas (SANTOS, 2006a).

Nesse sentido, a tradução de saberes concebe o universalismo como uma peculiaridade ocidental cuja supremacia como ideia reside nos interesses que a sustentam. Como contrapartida, Santos (2006a, p. 126) propõe que "a melhor formulação para o universalismo negativo talvez seja designá-lo como uma teoria geral residual: uma teoria geral sobre a impossibilidade de uma teoria geral", ou seja, a negação de que exista algo absoluto e válido para todas as culturas.

A partir dessa impossibilidade de domínio hegemônico do saber, o trabalho de tradução tanto pode ocorrer entre saberes hoje considerados hegemônicos e saberes não hegemônicos como entre diferentes saberes não hegemônicos. A importância deste último trabalho de tradução reside no fato de que somente por meio da inteligibilidade recíproca e consequente possibilidade de agregação entre saberes não hegemônicos é possível construir a contra-hegemonia (SANTOS, 2006a).

O segundo modo de trabalho de tradução encontra-se nas práticas sociais e seus agentes. Quando incide sobre as práticas, contudo, o trabalho de tradução visa a criar inteligibilidade recíproca entre formas de organização e objetivos de ação (SANTOS, 2006a). Desse modo, a tradução constitui um trabalho muito complexo, não somente pelo número e diversidade de movimentos e organizações envolvidos, mas, sobretudo, "pelo fato de uns e outras estarem ancorados em culturas e saberes muito diversos [...] os pontos em comum representam a possibilidade de uma agregação ou combinação a partir de baixo" (SANTOS, 2006a, p. 128).

Nesse sentido, o trabalho de tradução é complementar à sociologia das ausências e da sociologia das emergências. Estas últimas aumentam significativamente o número e diversidade das experiências disponíveis e possíveis, logo, o trabalho de tradução visa a criar inteligibilidade, coerência e articulação em um mundo enriquecido por essa multiplicidade e diversidade (SANTOS, 2006a).

Para Santos (2006a, p. 129), as condições e os procedimentos do trabalho de tradução podem ser esclarecidos a partir das respostas às seguintes questões: $O$ que traduzir? Entre o quê? Quem traduzir? Quando traduzir? Traduzir com quais objetivos?

A premissa essencial para a questão sobre o que traduzir é o conceito de zona de contato. Para Santos (2006a, p. 130) zonas de contato são "campos sociais onde diferentes mundos-da-vida normativos, práticas e conhecimentos se encontram, chocam e interagem". Ainda segundo o autor, as duas zonas de contato constitutivas da modernidade ocidental são a zona epistemológica, onde se confrontam a ciência moderna e os saberes leigos, tradicionais, dos camponeses, e a zona colonial, onde se defrontam o colonizador e o colonizado. Contudo, a zona de contato da razão cosmopolita considera que cabe a cada saber ou prática decidir o que e quem é posto em contato. Além desta, que o autor denomina seletividade ativa, existe a chamada seletividade passiva, quando, em caso de opressão extrema, algo em uma cultura se torna impronunciável. Dessa forma, as versões que contemplam um círculo mais amplo e inclusivo de reciprocidade são as que geram zonas de contato mais adequadas para que o trabalho de tradução seja aprofundado.

A seleção dos saberes e práticas, que explicam entre o que se deve realizar o trabalho de tradução, é sempre resultado de uma convergência ou conjugação de sensações de experiências de carência, de inconformismo e da motivação para superá-las de uma forma específica. Essas seleções dos saberes podem surgir como reação a uma zona de contato colonial e imperial ou por meio de zonas de conflito não imperiais, onde as relações entre os diferentes saberes e práticas são mais horizontais (SANTOS, 2006a).

Partindo da premissa de que os saberes e as práticas existem somente na medida em que sua utilização e execução estão presentes nos grupos sociais, Santos (2006a) considera que a tradução é sempre realizada entre representantes desses grupos sociais, uma vez que, argumentativo, o trabalho de tradução exige capacidade intelectual, todavia, de modo 
democrático. Dessa forma, Santos (2006a) acredita que a decisão acerca de quem traduzir tornar-se-á uma das mais decisivas deliberações na construção da globalização contra-hegemônica.

Para que a zona de contato não se torne imperial e o trabalho de tradução não se torne uma canibalização, Santos (2006a) defende que, quando traduzir, a zona de contato cosmopolita seja resultado de uma conjunção de tempos, ritmos e oportunidades. Portanto, a zona de contato deve ser vigiada, a fim de que a simultaneidade do contato não determine o colapso de uma das partes. Dessa forma, a seguir são colocados alguns dos desafios do trabalho de tradução no campo da administração.

\section{OS DESAFIOS DO TRABALHO DE TRADUÇÃO PARA A (RE)CONSTRUÇÃO DO CONHECIMENTO EM ADMINISTRAÇÃO}

A necessidade de traduzir reside no fato de que os problemas que o paradigma da modernidade ocidental, por meio da ciência positivista, procurou solucionar permanecem, em grande parte, a ser resolvidos e sua resolução é cada vez mais urgente (SANTOS, 2006a). Por esse motivo, o trabalho de tradução baseado na sociologia das ausências e na sociologia das emergências, de acordo com Santos (2006a, p. 134), é "um trabalho de imaginação epistemológica e de imaginação democrática com o objetivo de construir novas e plurais concepções de emancipação social sobre as ruínas da emancipação social automática do projeto moderno".

Diante desse cenário, há a necessidade de um debate acerca do desenvolvimento de "teorias organizacionais brasileiras". Serva (1990) destaca que a pesquisa acadêmica teria importância nesse processo, pois poderia mapear e analisar ações organizacionais, experiências concretas, iniciativas e novas soluções que vêm sendo aplicadas aos nossos problemas administrativos.

Acerca dos desafios da produção de conhecimento em administração no Brasil, o estrangeirismo na administração é também um dos problemas apontados por Alcadipani no painel promovido por Bertero, Alcadipani, Cabral et al. (2013). Alcadipani destaca que o estrangeirismo, aliado ao paroquialismo - "uma atitude desequilibrada na de teorias e da produção científica em geral, que acabam sendo sobreapreciados pelo fato de ser nacionais" (BERTERO, ALCADIPANI, CABRAL et al., 2013, p. 182) e ao produtivismo - produção de artigos acadêmicos apenas para cumprir quesitos de pontuação acadêmica -, leva a academia brasileira a produzir escritos com tão pouca contribuição teórica e originalidade.

No mesmo painel, Alexandre Faria apresenta os desafios geopolíticos para a pesquisa em administração. Para o autor, passamos por um processo de expansão das fronteiras do conhecimento. As ideias de Faria quanto à "expansão das fronteiras" fortalecem os conceitos de "paradigmas", de Kuhn (1978), e coadunam com a tese de Santos (2006a) quanto à expansão das fronteiras do conhecimento.

Esse processo de "expansão das fronteiras do conhecimento" se caracteriza por três vertentes principais. A primeira vertente, explicitada por Faria (BERTERO, ALCADIPANI, CABRAL et al., 2013), é a da "transformação sistemática de tudo o que não é conhecimento em conhecimento", fortalecendo a hegemonia de conhecimento do Norte, pois todo conhecimento tem um padrão definido segundo as bases setentrionais.

A segunda vertente discorre acerca da expansão das instituições e organizações que compõem e governam o sistema do conhecimento, ou seja, quem diz o que é e o que não é ciência. Esses dois pontos, por si sós, dão a ideia do envoltório protecionista da ciência (do Norte), moderna e hegemônica. A terceira e última vertente é o processo combinado de "desterritorialização" e "reterritorialização" do sistema do conhecimento, uma vez que

[...] devido à rápida expansão desse sistema, o não conhecimento e a não inclusão tornaram-se intoleráveis ou inaceitáveis tanto pela direita quanto pela esquerda, tanto pelo Sul global quanto pelo Norte global. A ideia de conhecimento sem fronteiras [...] proposta pela sociedade do conhecimento defende e promove a inclusão de todos, sem exceção - desde que os diferentes tipos de conhecimento (no plural) sejam convertidos em conhecimento (no singular) pelo sistema dominante 
do conhecimento - e reforça o argumento colonialista de que não existe e não deve existir nada fora desse sistema (BERTERO, ALCADIPANI, CABRAL et al., 2013, p. 187).

Dessa forma, Faria deixa claro que não existe vida fora desse sistema. Ser ou ser! Mais uma vez, a questão do fortalecimento da hegemonia do Norte está em pauta, pois cada vez mais as instituições de ensino brasileiras preocupam-se com sua internacionalização (ou melhor, euroamericanização) por meio de rankings e conceitos de instituições estrangeiras. O texto de Faria possibilita inferir uma questão: seriam as universidades brasileiras "nossas"? (BERTERO, ALCADIPANI, CABRAL et al., 2013, p. 187).

Esse argumento leva a um outro "retro" (o primeiro é a retroalimentação) de reflexão, o retrocesso - ao modo positivista. Cunhado por Alcadipani, o termo leva à reflexão a respeito da produção de artigos acadêmicos. Com a introdução dos quesitos de pontuação acadêmica para engrandecer o currículo Lattes, Alcadipani afirma que o produtivismo é "útil para inúmeros professores que podem continuar na pós-graduação sem fazer pesquisa" (BERTERO, ALCADIPANI, CABRAL et al., 2013, p. 191). Simplesmente é solicitado a acadêmicos que produzam artigos, independente de sua área de interesse. Desse modo, afirma Alcadipani, "uma grande parte dos periódicos nacionais funciona com o simples objetivo de escoar produção acadêmica sem qualidade" (BERTERO, ALCADIPANI, CABRAL et al., 2013, p. 191).

Em contraponto ao movimento de "adequação" das universidades e das produções científicas, é justo retomar o pensamento de Faria (BERTERO, ALCADIPANI, CABRAL et al., 2013), que adapta e apresenta um conjunto de conceitos voltados ao futuro da pesquisa em gestão proposto por Mignolo (2011): reocidentalização (foco na reconstrução da confiança voltada aos EUA, na reinvenção do capitalismo e na produção da ciência com grandes corporações), desocidentalização (extremo oposto do primeiro conceito, muda o foco para as economias emergentes) e descolonialidade (traz a percepção de que diversos mundos e conhecimentos coexistem - pensamento que coaduna com a ideologia de Boaventura de Sousa Santos). Com essa discussão levantada, sobre as formas de fazer ciência, principalmente na administração, o pensamento de Sachs (1986) também é uma forma de colocar em suspenso os conhecimentos do "Norte", principalmente ligado às concepções de desenvolvimento que se deseja. Desse modo, Sachs (1986) cunha a expressão ecodesenvolvimento (mais tarde também denominado desenvolvimento sustentável), conceito amplamente discutido em importantes congressos mundiais ${ }^{3}$ em busca de uma nova forma de desenvolvimento.

Primariamente aplicado à questão ecológica, o conceito surgiu a partir do embate entre os radicalistas do "crescimento selvagem" (sem a visão antropocêntrica de mundo) e do absolutismo ecológico (SACHS, 1986, p. 113). Justen e Moretto Neto (2013) destacam o conceito de desenvolvimento explorado por Sachs (1986): trata-se de "[...] um processo de aprendizagem da sociedade, orientado para identificação e satisfação, em base sustentável, de necessidades humanas, materiais e não materiais, social e culturalmente determinadas".

Dessa forma, Sachs (1986) chama a atenção para que haja um equilíbrio e não um radicalismo excêntrico de destruição ou de preservação. É necessária uma mudança de paradigma, como Kuhn (1978) afirma, ou um pensamento pós-abissal, na visão de Santos (2010). Sachs (1986) demonstra que o propósito do ecodesenvolvimento não é postular o não crescimento, todavia, impulsionar as ideias de que novas modalidades de crescimento são possíveis, "tanto no plano das finalidades como no dos instrumentais, procurando-se aproveitar as contribuições culturais das populações interessadas e transformar em recursos úteis os elementos do seu meio ambiente".

O ecodesenvolvimento visa a uma "dupla abertura" - ou pensar além da linha - do horizonte: receber e considerar visões de diferentes atores e conceitos. Com o intuito de melhorar a qualidade da vida social, Sachs (1986) desenvolve a ideia da aplicação do ecodesenvolvimento nas estratégias de desenvolvimento regional e microrregional, sendo possível que seja assimilado pelos atores sociais, e não transplantado ou repassado por meio da ideia de colonização ou importação. $\mathrm{O}$ autor ainda aponta a característica de um eufemismo utilizado com frequência por membros da academia e "consultores organizacionais":

[...] o eufemismo "transferência de ideias" delineia, na maior parte dos casos, uma situação que melhor corresponde ao conceito de efeito de dominação tal como define Perroux (1948): relações

${ }^{3}$ Relatório Founex, Declaração de Estocolmo de 1972 e Declaração de Cocoyoc de 1974 (SACHS, 2007). 
assimétricas e irreversíveis entre o vendedor (ou arrendador) de técnicas e o comprador, dando, em última instância, ao primeiro uma grande margem de controle sobre a produção e, mais geralmente, sobre as decisões do segundo (SACHS, 1986, p. 82).

Em suma, sem julgar aquilo que é correto ou errado, os três conceitos anteriores convivem, em um ciclo: ao mesmo tempo que a reocidentalização tenta reinventar o Ocidente e faz crescer o engajamento de pesquisadores com esse fim, estimula o "ódio" para que outros pesquisadores busquem afirmar ainda mais a desocidentalização (BERTERO, ALCADIPANI, CABRAL et al., 2013, p. 190). E, mais uma vez relembrando Boaventura de Sousa Santos, a busca insaciável por esses dois primeiros conceitos justifica a busca pela descolonialidade.

\section{CONSIDERAÇÕES FINAIS}

Quando a ciência moderna rompe com o senso comum, ela deixa de reconhecer e marginaliza outros saberes, cometendo, nas palavras de Boaventura, um verdadeiro "epistemicídio" contra os conhecimentos populares, tradicionais, leigos, artísticos, míticos, entre outros, em nome de uma ciência moderna. Essa ruptura epistemológica levou à destruição de conhecimentos locais, desperdiçando experiências cognitivas e marginalizando grupos sociais que construíram suas relações com base nesses conhecimentos (SANTOS, 2005).

Segundo Santos (2010), a hegemonia do pensamento moderno ocidental continua alimentando um sistema de exclusão, que divide o mundo entre Ocidente e Oriente, entre Norte e Sul, acentuando a realidade de exclusão, característica do período colonial.

O "Sul" é, para Boaventura, a metáfora do sofrimento humano causado pela modernidade capitalista (SANTOS, 2006b). Segundo Gaudêncio Frigotto, que prefacia outra obra (SANTOS, 2007), o sociólogo Boaventura está engajado na discussão teórica e no compromisso ético-político das lutas dos movimentos e organizações sociais e políticas, que apostam não apenas na emancipação política, mas, sobretudo, na emancipação humana e social.

Assim, por meio da sociologia das ausências e emergências e da ecologia de saberes - via processos de tradução -, Santos (2006a) propõe uma racionalidade mais ampla e mais cosmopolita que a racionalidade (hegemônica) moderna ocidental, é, desse modo, uma racionalidade que dê conta da diversidade epistemológica do mundo.

Para promover a diversidade e a pluralidade, não negligenciando ou recusando a ciência moderna, mas assegurando a coexistência de saberes ocidentais com práticas de saberes locais, deriva a ecologia dos saberes. Desse modo, a ecologia dos saberes questiona a lógica da monocultura do saber e do rigor científico, a partir da identificação de outros saberes e de outros critérios de rigor que operam em contextos e práticas sociais declarados não existentes (SANTOS, 2006a).

Pode-se inferir que, para o campo da administração no Brasil, bem como para outras ciências, e, orientando-se pelas ideias de Boaventura trazidas neste ensaio, é relevante que a ciência da administração também faça sua "ecologia de saberes", a fim de que possa aumentar suas possibilidades de experiências humanas, sociais e outras fontes que a razão indolente e a ciência moderna dissimularam.

Muitos dos problemas enfrentados hoje, advindos da importação de teorias e modelos estrangeiros, poderiam ser mais valorizados a partir de experiências locais, expandindo o presente, por meio da sociologia das ausências, e promovendo a inclusão de muitos grupos até agora afastados do conhecimento científico. A expansão do presente se dá, também, por meio do ecodesenvolvimento, apontado por Sachs (1986).

Da mesma forma que Boaventura de Sousa Santos vem propor um pensamento científico multifacetado e multiepistemológico, Sachs (1986) trouxe o conceito de equilíbrio, da ciência de dupla entrada. Desse modo, pode-se entender que Sachs (1986) também defende uma "ecologia de saberes".

O objetivo deste estudo foi apresentar as contribuições do pensamento do sociólogo Boaventura de Sousa Santos no campo da epistemologia e dialogar com problemáticas da formação da ciência e ensino da administração no Brasil, representados pelos estudos de Streck e Adams (2012), Bertero, Alcadipani, Cabral et al. (2013), Rodrigues e Carrieri (2001), Serva 
(1990; 1992), Vergara e Carvalho (1995) e Vergara e Pinto (2001). Foram apresentadas algumas inquietações a respeito da importação de teorias na administração, junto com a dificuldade de construir uma ciência administrativa brasileira.

Para a elaboração deste ensaio teórico, a evolução do paradigma positivista sob o ponto de vista de Merton foi retratada em contraposição com as visões de Boaventura de Sousa Santos; houve um aprofundamento acerca do trabalho de Santos (2006a), tratando das sociologias das ausências e emergências; foi proporcionado esclarecimento sobre o estrangeirismo na administração brasileira, apontando a necessidade do trabalho de tradução de Santos (2010); e também se buscou identificar os desafios desse trabalho de tradução no Brasil para uma reconstrução do conhecimento em administração.

Por fim, o pensamento de Alexandre Faria vem à tona:

[...] a área de Gestão no Brasil estará em condições de liderar transformações [...] por meio de um grande projeto que abraça a geopolítica do conhecimento, promove a substituição do universalismo eurocêntrico pela pluriversalidade e possibilita a construção de um mundo no qual diversos mundos e conhecimentos coexistem. Talvez seja pedir ou esperar demais da área de Gestão, mas também pode ser uma excelente oportunidade para reinventarmos a área (BERTERO, ALCADIPANI, CABRAL et al., 2013, p. 190).

Inspirando-se nas contribuições de Boaventura de Sousa Santos, a transformação epistemológica, por meio da ecologia de saberes, é importante na área da administração como alternativa ao Norte dominador. Independência não significa se isolar do mundo, mas ter autonomia para escolher e seguir seu próprio caminho: independência ou Norte! 


\section{REFERÊNCIAS}

BARBER, B. Resistance by scientists to scientific discovery. Science, v. 134 , p. $596-602,1961$

BERTERO, C. et al. Os desafios da produção do conhecimento em administração no Brasil. Cad. EBAPE.BR, v. 11, n. 1, p. 181-196, 2013.

BUNGE, M. A. Ciência e desenvolvimento. São Paulo: Edusp, 1980.

CERVO, A. L.; BERVIAN, P. A.; SILVA, R. Metodologia científica. 6. ed. São Paulo: Pearson Prentice Hall, 2007.

DUSSEL, E. Meditações anticartesianas sobre a origem do antidiscurso filosófico da modernidade. In: SANTOS, B. S.; MENESES, M. P. (Org.). Epistemologias do Sul. São Paulo: Cortez, 2010. 341-395 p.

FANON, F. Os condenados da terra. 2. Ed. Rio de Janeiro: Civilização Brasileira, 1979.

JUSTEN, C. E.; MORETTO NETO, L. Gestões do desenvolvimento e desenvolvimentos da gestão: da unilateralidade reificada à dialogicidade da simbiose homem/natureza. Cad. EBAPE.BR, v. 11, n. 2, p. 295-310, 2013.

KUHN, T. S. A estrutura das revoluções científicas. 2. ed. São Paulo: Perspectiva, 1978.

MARCONI, M. A; LAKATOS, E. M. Técnicas de pesquisa: planejamento e execução de pesquisas, amostragens e técnicas de pesquisa e elaboração, análise e interpretação de dados. 7. ed. São Paulo: Atlas, 2008.

MERTON, R. K. Sociologia: teoria e estrutura. São Paulo: Mestre Jou, 1970.

MIGNOLO, W. The darker side of Western modernity: global futures, decolonial options. London: Duke University Press, 2011.

MOTTA, F. C. P.; ALCADIPANI, R.; BRESLER, R. B. A valorização do estrangeiro como segregação nas organizações. Revista de Administração Contemporânea, v. 5, n. esp., p. 59-79, 2001.

PAES, K. D.; DELLAGNELO, E. H. Boaventura de Souza Santos e Guerreiro Ramos: um olhar crítico sobre as ausências e emergências em organizações. In: ENCONTRO NACIONAL DA ANPAD - EnANPAD, 36., 2012, Rio de Janeiro. Anais... Rio de Janeiro: ANPAD, 2012.

RAMOS, A. G. Administração e contexto brasileiro: esboço de uma teoria geral da administração. 2. ed. Rio de Janeiro: Ed. FGV, 1983.

RAMOS, A. G. A redução sociológica. 3. ed. Rio de Janeiro: Ed. UFRJ, 1996

RODRIGUES, S. B.; CARRIERI, A. P. A tradição anglo-saxônica nos estudos organizacionais brasileiros. Revista de Administração Contemporânea, v. 5, n. esp., p. 81-102, 2001.

SACHS, I. Ecodesenvolvimento: crescer sem destruir. São Paulo: Vértice, 1986.
SACHS, I. Rumo à ecossocioeconomia: teoria e prática do desenvolvimento. Org. Paulo Freire Vieira. São Paulo: Cortez, 2007.

SANTOS, B. S. Da sociologia da ciência à política científica. Revista Crítica de Ciências Sociais, v. 1, p. 11-56, 1978.

SANTOS, B. S. Semear outras soluções: os caminhos da biodiversidade e dos conhecimentos rivais. Rio de Janeiro: Civilização Brasileira, 2005

SANTOS, B. S. Para uma sociologia das ausências e uma sociologia das emergências. In: SANTOS, B. S. A gramática do tempo: para uma nova cultura política. São Paulo: Cortez, 2006a. 93-135 p.

SANTOS, B. S. A ecologia de saberes. In: SANTOS, B. S. A gramática do tempo: para uma nova cultura política. São Paulo: Cortez, 2006b. 137-165 p.

SANTOS, B. S. Renovar a teoria crítica e reinventar a emancipação social. São Paulo: Boitempo, 2007.

SANTOS, B. S. Para além do pensamento abissal: das linhas globais a uma ecologia de saberes. In: SANTOS, B. S.; MENESES, M. P. Epistemologias do Sul. São Paulo: Cortez, 2010. 31-83 p.

SERVA, M. A. Contribuições para uma teoria organizacional brasileira. Rev. Adm. Pública, v. 24, n. 2, p. 10-21, 1990.

SERVA, M. A. A importação de metodologias administrativas pelo Brasil: uma análise semiológica. Rev. Adm. Pública, v. 26, n. 4, p. 128-44, 1992

SERVA, M. A. O surgimento e o desenvolvimento da epistemologia da administração: inferências sobre a contribuição ao aperfeiçoamento da teoria administrativa. Revista Gestão Organizacional, v. 6, n. 3, p. 51-64, 2013.

STRECK, D. R,; ADAMS, T. Pesquisa em educação: os movimentos sociais e a reconstrução epistemológica num contexto de colonialidade. Educação e Pesquisa, v. 38, n. 1, p. 243-257, mar. 2012.

TAYLOR, F. W. Princípios de administração científica. 7. ed. São Paulo: Atlas, 1970.

TENÓRIO, F. G. Gestão social: uma perspectiva conceitual. Rev. Adm. Pública, v. 32, n. 5, p. 7-23, 1998.

VERGARA, S. C.; CARVALHO JR., D. de S. Nacionalidade dos autores referenciados na literatura brasileira sobre organizações. Revista Brasileira de Administração Contemporânea, v. 1, n. 6, p. 169188, 1995.

VERGARA, S. C.; PINTO, M. C. S. Referências teóricas em análise organizacional: um estudo das nacionalidades dos autores referenciados na literatura brasileira. Revista de Administração Contemporânea, v. 5, n. esp., p. 103-121, 2001

\footnotetext{
Lucas Rocha Juncklaus

Acadêmico de Mestrado do Programa de Pós-Graduação em Administração da Universidade Federal de Santa Catarina. E-mail: lucas.juncklaus@gmail.com
}

Tiago José Bini

Mestre pelo Programa de Pós-Graduação em Administração da Universidade Federal de Santa Catarina. E-mail: tiago_bini@yahoo.com.br

Luis Moretto Neto

Doutor em Engenharia de Produção pela Universidade Federal de Santa Catarina; Professor Doutor/Titular do Centro Universitário Universitário Internacional-UNINTER, em Curitiba(PR); aposentando da Universidade Federal de Santa Catarina-UFSC. E-mail: luis.moretto.neto@ufsc.br 